\title{
PACINADESTUDANTE
}

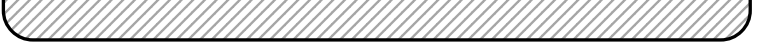

\section{ATITUDES DE DISCENTES DE ENFERMAGEM FRENTE AO COMPUTADOR}

\section{INTRODUÇÃO}

Na sociedade atual, não só o desempenho de qualquer atividade profissional, como o próprio relacionamento com o meio impõe o conhecimento da tecnologia computacional.

As experiências brasileiras em relação à enfermagem associada a computação, iniciadas a partir da década de 80 , demonstram a utilização do computador como auxiliar do enfermeiro tanto nas funções administrativas, assistenciais, educacionais como nas de pesquisa (SANTOS, 1981).

Para os enfermeiros proverem a qualidade do cuidado de enfermagem atual e futuramente, eles devem ser capazes de perceber o computador como uma ferramenta de trabalho (ANDRIOLI \& MUSSER, 1985). Em relação ao ensino e assistência de enfermagem são inúmeras e importantes as vantagens proporcionadas pela utilização da tecnologia computacional, visto o computador oferecer vantagens próprias, únicas e indispensáveis a ambas as áreas.

Para CIETTO (1986), não se pode questionar hoje a importância do estudo da informática no campo de enfermagem.

É tema de relevante importância a verificação e o conhecimento sobre as atitudes de discentes de enfermagem frente à utilização desta importante e atual "ferramenta de trabalho", o computador.

\section{OBJETIVOS}

Tem-se como objetivos para este estudo a identificação e comparação das atitudes de discentes
Paulo Celso Prado Telles Filho* Silvia Helena de Bortoli Cassiani**

de duas instituições de ensino superior em enfermagem sobre a utilização do computador.

\section{METODOLOGIA}

A população em estudo consta de discentes cursando o oitavo semestre das seguintes instituições em ensino superior de enfermagem: A (Universidade Estadual) e B (Universidade Particular), ambas localizadas no interior do Estado de São Paulo. Como instrumento de coleta de dados foram desenvolvidas e aplicadas nove escalas de Likert contendo três pontos que variam entre a discordância, indecisão e concordância em relação ao objeto de estudo. A análise dos dados deu-se com base no Programa Excel.

\section{DISCUSSÃO}

Inicialmente faz-se necessário citar que não houve diferença significativa entre as instituições analisadas.

Os dados coletados, assim se apresentam: $72 \%$ da amostra considera a simulação computadorizada como uma ligação entre o conhecimento teórico e a aplicação prática. O mais elevado índice de aprovação, no entanto, deu-se na afirmação: Considero o computador um instrumento de descobertas e informações, com 95\% de concordância, seguindo-se de $85 \%$ dos discentes que afirmam ser o computador um meio para obter-se excelentes resultados.

Em relação ao ensino auxiliado por computador enquanto fornecedor de melhores resultados que através de métodos tradicionais obteve-se $52 \%$ de aprovação e $44 \%$ de indecisão; já em relação aos Programas de

* Discente do $7^{\circ}$ semestre do Curso de Graduação da Escola de Enfermagem de Ribeirão Preto da Universidade de São Paulo, Bolsista do Programa Especial de Treinamento - CAPES/EERP-USP

** Professora Doutora do Departamento de Enfermagem Geral e Especializada da Escola de Enfermagem de Ribeirão Preto da Universidade de São Paulo e Tutora do Programa Especial de Treinamento - CAPES/EERP-USP 
Computação, como por exemplo Windows, Power Point e Corel Draw, como sendo facilitadores da "vida acadêmica", obteve-se $80 \%$ de aprovação.

Em relação a utilização do computador por discentes, os dados assim se apresentam: 73\% afirmam o computador ser um instrumento de larga utilização pelos discentes de nível superior, embora quando a afirmação dirija-se a si próprio, ou seja, eu utilizo muito o computador obtenha concordância de $59 \%$.

No que diz respeito à utilização pelos docentes $61 \%$ da amostra afirma a utilização do computador principalmente dirigida ao ensino e pesquisa.

O menor nível de concordância deu-se na afirmação: há grande incentivo à utilização do computador pela Universidade, com $38 \%$.

\section{CONCLUSÕES}

A informática tem sido utilizada em inúmeras atividades humanas. O elo entre a saúde e tecnologia é fator a ser estudado e valorizado pelos profissionais da área da saúde, visto atualmente vivenciar-se inovações científicas e tecnológicas em ritmo acelerado (SCOCHI et al., 1991).

Pode-se perceber, através deste estudo, o nível de aceitação e a positividade de discentes da área de enfermagem em relação a utilização do recurso computacional. No entanto, alguns aspectos destacamse sobremaneira dentre os quais vale citar: o computador como instrumento de descobertas, informações e meio para a obtenção de excelentes resultados.

Evidenciou-se, também a critica em relação a postura assumida pelas universidades de insuficiente incentivo a utilização do computador.

O estudo demonstra claramente a concordância dos discentes da área de enfermagem com a seguinte afirmação: populações futuras serão compostas por alfabetizados e analfabetos em computação: profissões que desejem conviver com outras esferas da sociedade devem alfabetizar-se ADAMS, 1986.

\section{REFERÊNCIAS BILBLIOGRÁFICAS}

01. ADAMS, G.A. Computer technology: its impact on nursing pratice Nursing Administration Quartely, v.10, n.2.p.21-33, 1986.

02. ANDRIOLI, K.; MUSSER, L.A. Computer in nursing care: the state of the art. Nursing Outlook, v.33, n.1, p.16-21, jan./fev. 1985.

03. CIETO, L. O impacto da informática na enfermagem. Revista Brasileira de Informática em Saúde, São Paulo, n.1, p. 15-19, set./out. 1986.

04. SANTOS, B.R.L.; SCOCHI, C.G.S.; ÉVORA, Y.D.M. O computador como instrumento de apoio na pesquisa e no ensino de enfermagem. In: CONGRESSO BRASILEIRO DE ENFERMAGEM, 39, Salvador, Bahia, nov. 1981.

05. SCOCHI, C.G.S.; LUIS, M.V.; RODRIGUES, R.A.P.; ÉVORA, Y.D.M. A implantação da informática em instituições de ensino: experiência da Escola de Enfermagem de Ribeirão Preto USP. Revista Paulista de Enfermagem, v.10, n.2, p. 79-86 mai./ago. 1991. 